\title{
ARQUITETURA ESCOLAR INCLUSIVA: REFLEXÕES SOBRE A ACESSIBILIDADE NA EXPERIÊNCIA DA EXTENSÃO UNIVERSITÁRIA
}

INCLUSIVE SCHOOL ARCHITECTURE: REFLECTIONS ON ACCESSIBILITY IN THE

EXPERIENCE OF UNIVERSITY EXTENSION

\begin{abstract}
Aline Eyng Savi ${ }^{1}$,Elaine Guglielmi Pavei Antunes ${ }^{2}$, Haron Fabre ${ }^{2}$, Pedro Luiz Kestering Medeiros $^{2}$, Tainara Calabrez ${ }^{2}$
\end{abstract}

\begin{abstract}
RESUMO
Este é um relato de experiência vivenciado pelos participantes do Projeto de Extensão "Observatório Acessível" do Programa Inovação para Sustentabilidade, com a participação dos cursos de Arquitetura e Urbanismo, Design de Produtos e Engenharia Civil da Universidade do Extremo Sul Catarinense e que teve duração entre os anos de 2018 e 2020 . O projeto objetivou propor subsídios de tecnologia assistiva para qualificação e adequação da acessibilidade espacial de espaços internos e externos nas escolas municipais de Morro da Fumaça. Foram realizados vários encontros e abordagens sobre o tema da acessibilidade espacial nas escolas. Dessa forma, o objetivo do projeto foi alcançado, pois foram elaboradas diretrizes para o projeto arquitetônico de escolas acessíveis; e constatou-se que as condições ambientais e arquitetônicas das escolas apresentavam obstáculos à acessibilidade, prejudicando a autonomia dos alunos com deficiência. Por fỉm, destaca-se o enriquecimento de saberes pelos extensionistas através do contato e da construção de um diálogo mais empático com o outro.Sabe-se que garantir o acesso espacial e o uso dos ambientes é uma condição básica para que se alcancem metas maiores de inclusão na escola.
\end{abstract}

Palavras-Chave: Acessibilidade espacial. Avaliação Pós-ocupação.Educação Inclusiva. Projeto de Extensão.

\footnotetext{
ABSTRACT

This is an experience report experienced by the participants of the "Accessible Observatory" Extension Project of the Innovation for Sustainability Program, with the participation of the Architecture and Urbanism, Product Design and Civil Engineering courses at the University of the Extreme South of Santa Catarina and which lasted between the years 2018 and 2020. The project aimed to propose subsidies for assistive technology for qualifying and adapting the spatial accessibility of internal and external spaces in the municipal schools of Morro da Fumaça. Several meetings and approaches were held on the topic of spatial accessibility in schools. In this way, the objective of the project was achieved, as guidelines were drawn up for the architectural design of schools obtained; and it was found that the environmental and architectural conditions of the schools presented locks to accessibility, impairing the autonomy of students with disabilities. Finally, it is highlighted the extension of knowledge by extensionists through contact and the construction of a more empathic dialogue with each

${ }^{1}$ Universidade do Extremo Sul Catarinense, Endereço postal: Rua Emilio de Menezes, 355, Criciúma-SC, CEP: 88810-260 - e-mail: arquiteta.alinesavi@gmail.com.

${ }^{2}$ Universidade do Extremo Sul Catarinense.
} 
other. It is known that ensuring spatial access and the use of environments is a basic condition for achieving greater goals. inclusion in the school.

Keywords: Spatialaccessibility. Post-occupationAssessment. Inclusive Education.Extension Project.

\section{INTRODUÇÃO}

A escola tem o papel no processo evolutivo do ser humano, participando na vida coletiva com possibilidade de ensinar direitos, deveres e respeito ao próximo. É um dos locais onde uma pessoa deveria se constituir como ser pensante e questionador, despertando potenciais criativos, curiosidades e talentos em diferentes formas de expressão. A educação por tal importância, avança além da pedagogia, constituindo estudo para diferentes áreas do conhecimento. Do ponto de vista da Arquitetura, um bom espaço físico escolar é aquele reconhecido pela representatividade, com parâmetros centrados nas vivências e nos usos, incluindo aspectos de acessibilidade e ergonomia.

A qualidade arquitetônica do ambiente escolar influencia diretamente o aprendizado; e na situação de pessoas com deficiência, é um fator determinante para a inclusão pois possibilita a autonomia (KOWALTOWSKI, 2011). A acessibilidade espacial escolar significa bem mais do que apenas poder chegar ou entrar num lugar desejado. É, também, necessário que a pessoa possa situar-se, orientar-se no espaço e que compreenda o que acontece, a fim de encontrar os diversos lugares e ambientes com suas diferentes atividades, sem precisar ser auxiliado. Um lugar acessível deve permitir, através da maneira como está construído e das características de seu mobiliário, que todos possam participar das atividades existentes e que utilizem os espaços e equipamentos com igualdade e independência na medida de suas possibilidades (DISCHINGER, et al, 2009).

Na situação das escolas brasileiras, registra-se que os marcos legais históricos são motivos para o crescimento a cada ano das matrículas no ensino regular de alunos com deficiência. Ainda que lentamente, o Brasil avança, mesmo com o quadro deficitário de infraestrutura das escolas. Há de se considerar, contudo, que o número de evasão escolar desses mesmos alunos é expressivo, e entre os motivos estãoas más condições de acessibilidade espacial (BRASIL, 2019).

Para garantir condições de acessibilidade espacial nas escolas, é importante identificar quais barreiras aumentam o grau de dificuldade ou impossibilitam a participação, a realização de atividades e a interação das pessoas com deficiência. Referente ao espaço, as 
barreiras físicas podem ser naturais ou construídas, dificultando ou impedindo a realização de atividades desejadas de forma independente.

Em consonância com ações de fortalecimento das políticas públicas na área de inclusão escolar no Brasil, o projeto de extensão "Observatório Acessível” investigou as condições de acessibilidade espacial nas escolas municipais de Morro da Fumaça, sul do estado de Santa Catarina, Brasil. O grupo de trabalho reuniu os seguintes cursos da Universidade do Extremo Sul Catarinense: Arquitetura e Urbanismo, Design de Produtos e Engenharia Civil, focados na aplicação de instrumentos metodológicos para a avaliação pósocupação e com o intuito de compreender a condição atual das edificações escolares no que tange à acessibilidade espacial.

O presente artigo apresenta portanto, o relato de experiência extensionista vivenciado entre os anos de 2018 e 2020 e com a parceria do Observatório Social do município. O projeto atuou por meio de encontros mensais às escolas para promoção de diferentes avaliações e trabalhos semanais de análise e elaboração de relatórios. O relato apresenta as experiências universitárias, os instrumentos metodológicos adotados, bem como discute os resultados encontrados e por fim, reflete acerca das repercussões dessa vivência extensionista para a formação acadêmica e comunidade externa.

\section{FUNDAMENTAÇÃO TEÓRICA}

A arquitetura escolar brasileira historicamente apresenta a preocupação funcionalista de atender a demanda de vagas aos estudantes, em detrimento a outros condicionantes que deveriam aliar-se para agregar qualidade aos edifícios corroborando para melhorias também, no ensino realizado. Seriam elas: conforto ambiental (térmico, visual, acústico, olfativo/qualidade do ar); qualidade sanitária dos ambientes; a adequação dos ambientes internos e externos (arranjo espacial, volumetria, materiais, cores e texturas) com as práticas pedagógicas, a cultura e osdiferentes níveis de desenvolvimento humano; bem como a acessibilidade universal, envolvendo o conceito de ambientes inclusivos (KOWALTOWSKI, 2011).

Embora, os conceitos de quantidade (demanda por vagas) e qualidade não sejam excludentes entre si, na realidade nacional sua articulação nem sempre ocorre, agravando-se em obras públicas. O processo de projeto arquitetônico que deveria considerar estudos de viabilidade, definição das características ambientais e outros condicionantes específicos, é 
terceirizado e os responsáveis projetam modelos "padrão". O resultado são edificações cuja inadequação inicia no programa arquitetônico, chegando a sua conclusão e uso, requerendo contínuas adaptações.

No espaço, a experiência do humana ocorre por meio da apropriação, uso e percepções dos sentidos, que funcionam como mecanismos para o processo de desenvolvimento cognitivo. No ambiente escolar, os conceitos quantitativos corroboram para o desenvolvimento saudável ao permitirem a participação de todas as atividades com autonomia. Por essa razão, é necessário que o projeto arquitetônico considere os aspectos de qualidade supracitados, entre eles, as questões de acessibilidade universal.As edificações que ponderam tais fatores na fase de projeto, são até mesmo mais sustentáveis economicamente, visto que irão requerer menor número de adaptações em seu uso.

Para que uma escola possa ser entendida como inclusiva, o espaço físico deve ser pensado sobre a perspectiva da diversidade humana. Nesse sentido, a acessibilidade escolar deve considerar a dimensão psicossocial dos espaços construídos pelas trocas entre os indivíduos e a sociedade, sendo necessário produzir mudanças na estrutura escolar, nos espaços de formação de professores, nas atitudes do outro e em nós mesmos (CARVALHO, 2008).

A inclusão escolar é um processo sistêmico, uma engrenagem complexa, composta por vários elementos, na falta de um destes, pode-se criar barreiras, privando ou interrompendo essa ação, com lacunas na vida social do aluno com deficiência. Segundo Padilha (2014), tornar inclusivo o sistema educacional exigeuma nova postura públicasendo imprescindível que o tema se torne, de fato, prioridade na agenda governamental, pois exige conscientização, ampla participação, planejamento, financiamento e tempo; devendo ser base de uma política de Estado.

A discussão sobre acessibilidade na escola ganha importância pelo desafio do acesso, da permanência e da participação de todas as pessoas, sem que haja nenhuma exclusão.Temse a Constituição de 1988 (BRASIL, 2012) como fundamento de validade para a defesa da inclusão. Nas últimas duas décadas, houve avanços em relação à política e legislação da educação especial na perspectiva da educação inclusiva. Foram criadas diversas leis que beneficiaram a Política Nacional da Educação Especial. Esta, por sua vez,é sustentada por três eixos: leis fundamentadas na concepção de educação inclusiva; políticas de financiamento para a oferta de recursos e serviços para a eliminação das barreiras no processo de escolarização; e orientações para práticas pedagógicas inclusivas (BRASIL, 2008).

Tais medidas ocorreram com o respaldo da Convenção sobre os Direitos das Pessoas 
com Deficiência (ONU, 2006). Nela ponderou-se a necessidade de identificação e eliminação, por parte dos estados e municípios, das barreiras físicas presentes nos ambientes internos e externose que prejudicam o acesso aos espaços públicos, incluindo as escolas. Desde então, o que se contatouforaminiciativas (muitas vezes desarticuladas) para promover a inclusão escolar por parte do poder público e com relativa fiscalização da sociedade civil. O resultado é ainda tímido, incluindo a questão de acessibilidade espacial, concentrando-se na colocação de rampas e pisos táteis, deixando para atrás outras barreira, além de permanecerem várias resistências à efetivação prática de projetos institucionais inclusivos (MICHELS, 2011).

A acessibilidade é a possibilidade e condição de alcance, percepção e entendimento para a utilização com segurança e autonomia de edificações, espaço, mobiliário, equipamento urbano e outros elementos (ABNT, 2015). A acessibilidade física corresponde a todos os espaços onde existe a premissa da circulação humana. Segundo Dischinger, et al (2009), a acessibilidade espacial, é intrínseca à arquitetônica, pois possibilita a pessoa sentir-se, orientar-se e compreender o que acontece a sua volta e assim poder explorar os ambientes com independência.

Para orientar as ações de avaliação e fiscalização da acessibilidade espacial no ambiente público, Dischinger, Bins Ely e Piardi (2012), classificam em quatro categorias os componentes da acessibilidade espacial: a orientação espacial, comunicação, deslocamento e uso. Cada uma dessas categorias apresenta um conjunto de diretrizes que devem ser cumpridas a fim garantir a acessibilidade em edifícios públicos (entre eles escolas) e minimizar as restrições aos usuários. Vale ressaltar que acessibilidade espacial depende do cumprimento de tais diretrizes como um todo, e a falha em cumprir apenas uma delas pode comprometer todos os demais itens.

A orientação espacial diz respeito às características que fazem o usuário reconhecer a identidade e as funções do espaço, para definir estratégias de deslocamento e uso. Vários processos interligados ocorrem para que o indivíduo possa se orientar no espaço. Primeiro, é necessário obter informações do ambiente por meio da percepção. Depois, essas informações são processadas cognitivamente, permitindo a elaboração mental de representações e a definição de ações. Sendo assim, as condições de orientação dependem tanto de elementos arquitetônicos e informativos do local (como placas, cores, sinais, letreiros e etc.) como da condição do indivíduo de processar essas informações, tomar decisões e agir (BINS ELY; BRANDÃO; BERTOLETTI, 2010). 
A comunicação diz respeito à possibilidade da troca de informações interpessoais, ou troca de informações entre o usuário e o equipamento utilizado. Deve ser possível, por exemplo, que um aluno cego tenha acesso à livros em braile, assim como professores pedagogicamente preparados para atender a esse tipo de necessidade. "A informação deve ser acessível a todos" (DISCHINGER; BINS ELY; PIARDI, 2012, p. 30) e avaliar as condições de comunicação é fundamental para garantir e melhorar a independência de pessoas.

As condições de deslocamento em ambientes públicos dizem respeito a possibilidade de qualquer pessoa poder movimentar-se de maneira independente, com seu conforto e segurança assegurados, a fim de chegar ao local desejado (ABATE, et al, 2011).

As condições de uso dos espaços e dos equipamentos referem-se à possibilidade de realização das atividades por todas as pessoas. Os equipamentos em salas de aula, banheiros e demais ambientes públicos devem estar adequados às normas de acessibilidade, por exemplo (DISCHINGER; BINS ELY; PIARDI, 2012).

Ao viabilizar acessibilidade espacial, a percepção dessa experiência faz com que o indivíduo confira significado ao mundo social e isso, tem um papel importante no trabalho educativo, especialmente na inclusão escolar. Segundo Rocha (2002), uma educação interessada no crescimento do indivíduo deve privilegiar a percepção como um conhecimento da realidade, um conhecimento situado porque a percepção também, está vinculada aos valores desenvolvidos e estimulados pelas diferenças do ser humano.

Logo, para poder realizar as alterações necessárias a fim de garantir aos usuários uma certa qualidade em acessibilidade espacial, é necessário compreender os diferentes tipos de deficiência e suas necessidades para a realização de atividades. Depois, deve-se saber identificar quais são as barreiras espaciais que impedem a realização de tais atividades.

\section{PROCEDIMENTOS METODOLÓGICOS}

O projeto de extensão “Observatório Acessível - Subsídios das tecnologias assistivas para adequação e qualificação de acessibilidade espacial em escolas do município de Morro da Fumaça em parceira com o Observatório Social”, insere-se no Programa de Extensão Inovação para Sustentabilidade, da Universidade do Extremo Sul Catarinense.A inserção nesse programa corroborou com o entendimento institucional do "ser social sustentável", que cria diversas relações pressupondo um convívio harmônico com os outros indivíduos e com o ambiente, segundo suas condições e os recursos disponibilizados sejam naturais ou construídos. Essa postura reflete diretamente na qualidade de vida e na maneira como o 
espaço é utilizado. Nesse caso, a relação dos alunos com deficiência nas escolas e consequentemente, o fator de inclusão.

O projeto de extensão "Observatório Acessível” teve o objetivo geral de propor subsídios de tecnologia assistiva para qualificação e adequação da acessibilidade espacial de espaços internos e externos nas escolas municipais de Morro da Fumaça.

Sobre tecnologias assistivas entende-se como o rol de recursos e serviços que contribuem para proporcionar ou ampliar habilidades funcionais de pessoas com deficiência, consequentemente promovendo autonomia e inclusão (COMITÊ DE AJUDAS TÉCNICAS, 2009). Nesse projeto, foram todos os recursos para atender aos componentes da acessibilidade espacial: a orientação espacial, comunicação, deslocamento e uso, supracitados.

A demanda para o projeto de extensão foi apresentada pelo Observatório Social Morro da Fumaça, que se organiza em diferentes núcleos para fiscalização do poder público municipal, entre elas, a análise das condições de acessibilidade espacial nas edificações de uso público. Conforme solicitação, o projeto investigou a infraestrutura desete escolas (totalidade do universo) (Figura 1).

Figura 1: Mapa indicativo das sete escolas municipais visitadas.

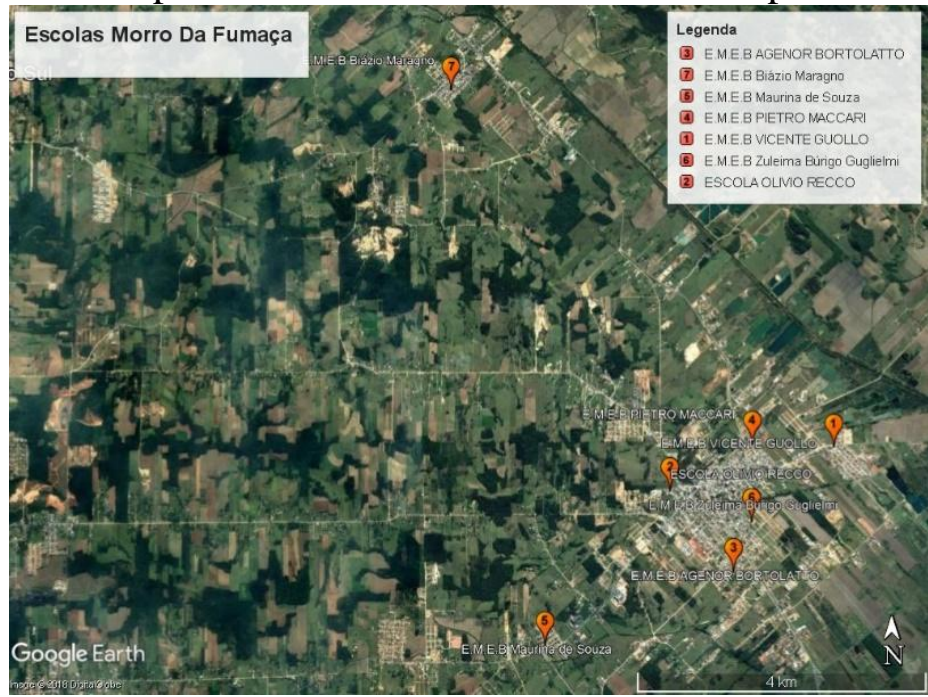

Fonte: Autores, 2018.

O ensino público municipal de Morro da Fumaça atende creche, pré-escola e o fundamental. Contudo, o projeto de extensão analisou apenas os espaços de pré-escola e ensino fundamental. A opção por não investigar as creches ocorreu porque elas respondem por legislação específica, variando inclusive as questões de acessibilidade espacial.

Para alcançar o objetivo proposto, o desenvolvimento do projeto de extensão 
considerou o embasamento da "pesquisa-ação", possibilitando que os extensionistas intervissem dentro de uma problemática social, analisando-a e anunciando seu objetivo de forma a mobilizar os participantes a construírem novos saberes (THIOLLENT, 2005).

Como promoção positiva do projeto, considerou-se conforme Thiollent (2005): (01) tratar de tópicos de interesse social, no sentido de compreender a acessibilidade espacial, consolidando os direitos constitucionais de ir e vir e à educação; (02) permitir que todos os envolvidos participassem ativamente, no entendimento da integração necessária; e por fim, (03) estabelecer procedimentos de inclusão, para o acesso universal ao ambiente escolar, independentemente da condição ou não de deficiência.

As etapas de trabalho foram divididas em fases (Quadro 1), cujo processo foi continuamente avaliado a partir de reuniões da equipe, incluindo docentes e discentes extensionistas. Durante todas as etapas foram produzidos registros das atividades, a partir de fotografias, áudios, vídeos e anotações de campo, que apoiaram a elaboração de relatórios de acompanhamento e a socialização dos resultados.

Quadro 01: Síntese das atividades a serem desenvolvidas.

\begin{tabular}{|c|c|c|}
\hline ETAPAS DE TRABALHO & MÉTODOS E TÉCNICAS & PARTICIPANTES \\
\hline \multirow{2}{*}{ Fase de Diagnóstico } & Pesquisa bibliográfica & Bolsistas e Professores \\
\cline { 2 - 3 } & Reunião de trabalho de grupo & $\begin{array}{c}\text { Externas: comunidade acadêmica, } \\
\text { escolar e Observatório Social }\end{array}$ \\
\cline { 2 - 3 } & $\begin{array}{c}\text { Aplicação das planilhas de } \\
\text { avaliação espacial (em cada uma } \\
\text { das escolas) }\end{array}$ & $\begin{array}{c}\text { Bolsistas e Professores (em cada } \\
\text { uma das escolas) }\end{array}$ \\
\hline \multirow{2}{*}{ Fase Propositiva } & $\begin{array}{c}\text { Elaboração dos relatórios (para } \\
\text { cada uma das escolas) }\end{array}$ & Bolsistas e Professores \\
\hline Fase de Avaliação & $\begin{array}{c}\text { Revisão dos materiais produzidos e } \\
\text { compilação }\end{array}$ & Bolsistas e Professores \\
\hline
\end{tabular}

Fonte: Autores, 2018.

A Fase de Diagnóstico consistiu inicialmente, em reuniões de trabalho com definição do cronograma de atividades e troca de informações sobre o projeto, estabelecimento de bibliografias para aproximação conceitual pelos extensionistas, sendo relacionadas aos temas: ensino e educação inclusiva, arquitetura escolar, pessoas com deficiência, acessibilidade, tecnologias assistivas, legislações específicas e metodologias de avaliação pós-ocupação. A importância dessa etapa corrobora com o entendimento de Paulo Freire (1992) sobre a responsabilidade ética, política e profissional do "ensinante" no dever de se preparar, de se capacitar, de se formar antes mesmo de iniciar sua atividade.

Nessa fase foi aplicado o principal instrumento de avaliação pós-ocupação da 
acessibilidade espacial nas escolas, "Manual de Acessibilidade Espacial para Escolas: o direito à escola acessível" (DISCHINGER, et al, 2009). O "Manual” identifica as dificuldades encontradas por alunos com deficiência no uso dos espaços e equipamentos escolares. Sua aplicação relaciona a norma brasileira de acessibilidade aos ambientes e aspectos ergonômicos, declarando-os aptos, ou não, a receber qualquer aluno, considerando o espaço físico e equipamentos, que devem estar preparados para garantir acessibilidade. Registra-se que o "Manual" apresenta condições previstas pela Associação Brasileira de Normas Técnicas na NBR 9050 de 2004. Como esta foi revisada em 2015, houve a readequação do Manual pela equipe do projeto de extensão. Após essa atividade, a aplicação ocorreu em todas as escolas municipais. Vale salientar que participavam das visitas todos extensionistas (docentes e discentes).

O resultado da aplicação do "Manual" consistiu na elaboração e entrega de relatórios que correspondema Fase Propositiva. Nela foram elaborados documentos a partir de textos e ilustrações, onde para cada um dos ambientes escolares,os principais problemas de acessibilidade e os respectivos subsídios de tecnologia assistiva para soluciona-los foram apresentados.

A entrega de relatórios técnicos com as propostas de subsídios de tecnologias assistivas para a acessibilidade espacial dos espaços internos e externos nas escolas buscou contribuir para o maior entendimento das questões de acessibilidade espacial pelos gestores do ambiente (corpo diretivo das escolas). O material posteriormente, em trâmites de realização de obras de requalificação,permite a reivindicação de soluções mais assertivas, visto que é comum a informalidade na execução de reformas relacionadas a assunto.

Além disso, os relatórios serviram de ferramenta de cobrança do Observatório Social junto aos órgãos públicos municipais, corroborando para alcançar a missão - "Ser uma rede nacional propulsora do controle social para o aprimoramento da gestão pública e integridade empresarial" - e o objetivo da entidade (OBSERVATÓRIO SOCIAL, 2018).

A Fase final - Avaliação - ocorreu de maneira continuada durante a realização do projeto, a partir de reuniões da equipe e também, ao final de cada etapa de trabalho em cada uma das escolas. Como produto foi desenvolvido também, um canal nas mídias sociais, para registro do processo de trabalho ao longo da extensão.

O projeto de extensão seguindo o embasamento de "pesquisa-ação" (THIOLLENT, 2005) estruturou-se portanto, por meio das três fases e com a utilização dos instrumentos 
apresentados para propor reflexões sobre o tema da acessibilidade espacial e da condição da pessoa com deficiência na escola, bem como em toda sociedade. Nesse sentido, os participantes se fizeram sujeitos ativos, inclusive no compartilhamento de suas vivências.

Cabe ressaltar que não houve necessidade de submissão ao Comitê de Ética em Pesquisa, visto que o projeto não apresentou risco e nem envolvia seres humanos, apenas a avaliação espacial.

\section{RESULTADOS E DISCUSSÃO}

O universo participante do projeto de extensão equivaleu a 1.888 alunos matriculados. Desse total, 111 alunos classificados com deficiência, segundo dados encaminhados pelas escolas ao Censo Escolar de 2019. Ressalva-se que o número alto (cerca de $5 \%$ do total) inclui alunos com dificuldade de aprendizagem. Se considerados exclusivamente as pessoas com deficiência, conforme classificação médica (visual, auditiva, intelectual, física e múltipla), o número reduziria para 21 alunos (cerca de 1\%).

Essa divergência numérica aponta questões relevantes sobre a dificuldade de entendimento dos temas: pessoas com deficiência e acessibilidade espacial nas escolas brasileiras. Ainda que tecnologias assistivas possam ser adotadas para melhorar o aprendizado em casos de transtornos como o déficit de atenção por exemplo, tais alunos não deveriam ser classificados como pessoas com deficiência.

Sobre o assunto, Aran (2002) reforça a necessidade de atençãopara que não se mantenha ou provoque a desigualdade. Ainda que a educação inclusiva deva ser entendida como a presença de crianças e jovens com necessidades educativas especiais em classes comuns do ensino regular, isso não implica numa classificação única. É necessária a particularização dos grupos para fins estatísticos, tornando possível traçar estratégias coerentes a cada um.

Nesse projeto, a escolha pela "pesquisa-ação" revelou-se como um importante caminho para a concretizar as etapas de trabalho, que refletiram a teoria e a prática dos três cursos participantes do projeto de extensão (Arquitetura e Urbanismo, Design de Produtos e Engenharia Civil) e ao mesmo tempo, promoveram intervenções no cotidiano, com mudanças graduais do entendimento acerca do tema da pessoa com deficiência e sua inserção do ambiente construído, bem como o fomentodo respeito às diferenças a partir de uma ação sistemática.

Nesse sentido, a metodologia permitiu articular teoria e prática no mesmo processo 
de produção de conhecimento, entendendo-a como um caminho acadêmico tão válido quanto os demais, conforme discute Thiollent (2005). Além de viabilizar que a práticaextensionistafosse pautada na construção coletiva de conhecimentos entre os diversos atores internos e externos à Universidade, que desenvolveram as atividades em conjunto.

A Fase 01 do projeto estruturou-se em três etapas de trabalho. Dela participaram 11 acadêmicos e 06 professores extensionistas,organizando-se na coordenação e acompanhamento das atividades internas e junto à comunidade.As atividades ocorreram semanalmente, a partir de calendário com definição de objetivos a serem cumpridos. Inicialmente, houve o contato com o Observatório Social e a Secretaria de Educação para apresentação do trabalho (Figura 2). Essaaproximação inicial entre a equipe interna e externa, durou os três primeiros meses do projeto, em 2018.

Figura 2: Reunião com o Observatório Social para apresentação do projeto de extensão e formalização da parceria.

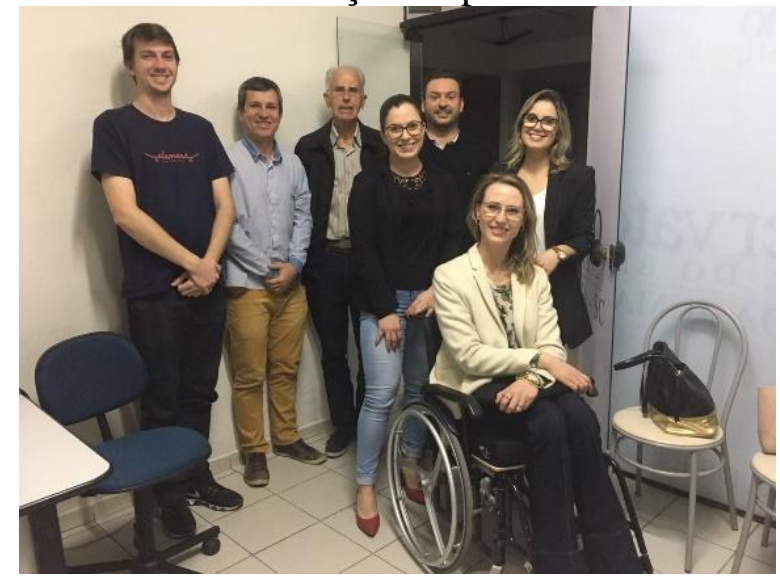

Fonte: Autores, 2018.

Em paralelo às atividades anteriores, foram realizados seminários temáticos para melhor compreensão do referencial teórico abordado. Essa etapa completou o primeiro semestre do projeto de extensão. Para o grupo de extensionistas, a troca de experiências permitiu a aproximação com temas interdisciplinares, resultantes do principal - acessibilidade espacial. Essa etapa alinhou-se ao entendimento de Freire (1992) sobre a necessidade de questionar continuamente para aprofundamento do aprendizado.

Ainda na fase 01 de Diagnóstico, ocorreram as avaliações pós-ocupação nas escolas. Nessa etapa participaram todos os extensionistas, docente e discentes. Cada escola foi visitada uma vez para aplicação do "Manual" e outra para entrega do relatório final (Figura 3). Nesse interim, foram organizados os dados e elaborado o documento. O processo durou em média 
45 dias por escola, resultando num período de um ano para completarem todas as sete visitas.

Figura 3: Visita para aplicação do "Manual” e para entrega do relatório à escola municipal Vicente Guollo.
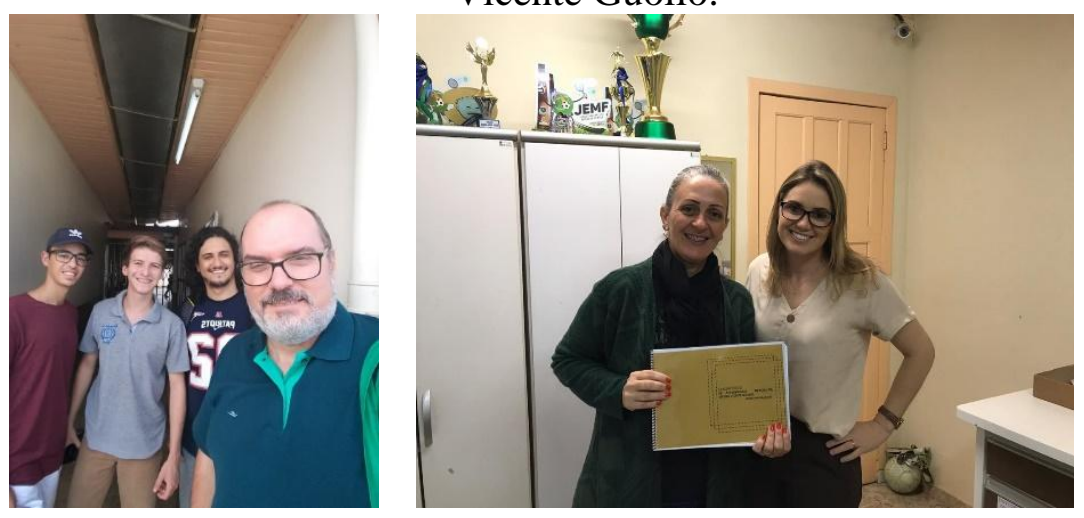

Fonte: Autores, 2019.

Das avaliações, é possível afirmar que as escolas funcionam em prédios próprios, geralmente divididosem blocos, que abrigam diversas funções. As edificações passaram por diferentes ampliações, refletidas na tipologia dos blocos. A unidade dessas arquiteturas ocorre por meio da materialidade de acabamento, com a pintura de cores uniformes nos blocos e muitas delas, possuem patologias construtivas, especialmente em estruturas de forro e piso.

Sobre a acessibilidade, os dados coletados no Censo Escolar de 2019 (último divulgado) apontaram que no cenário de realização do projeto todas as escolas atendiam alunos com deficiência e apenas 11\% tinham dependências acessíveis (01 escola) e 56\% possuíam banheiros adaptados (05 escolas). Registra-se que esses são os únicos critérios referentes à acessibilidade espacial considerados pela pesquisa nacional oficial e os mesmos são preenchidos pelos diretores das escolas.

Após a aplicação do "Manual", os resultados confirmaram os dados registrados no Censo Escolar (supracitado) e acrescentaram apontamentos desde o ambiente de entrada até o interior dos edifícios, conforme apresenta o Quadro 2 a seguir. Quase todas as escolas analisadas, necessitam de modificações para promoção da acessibilidade espacial, pois foram verificadas barreiras físicas como degraus no acesso às salas de aulas, banheiros sem adaptação adequada, mobiliárionão ergonômicos,ausência de piso guia, entre outras tecnologias assistivas.

Quadro 2: Síntese dos resultados encontrados na avaliação espacial realizada na totalidade das escolas.

\begin{tabular}{|l|l|l|l|}
\hline AMBIENTE & CONCLUSÕES & RESULTADOS & IMAGENS DE DIFERENTES \\
\hline
\end{tabular}




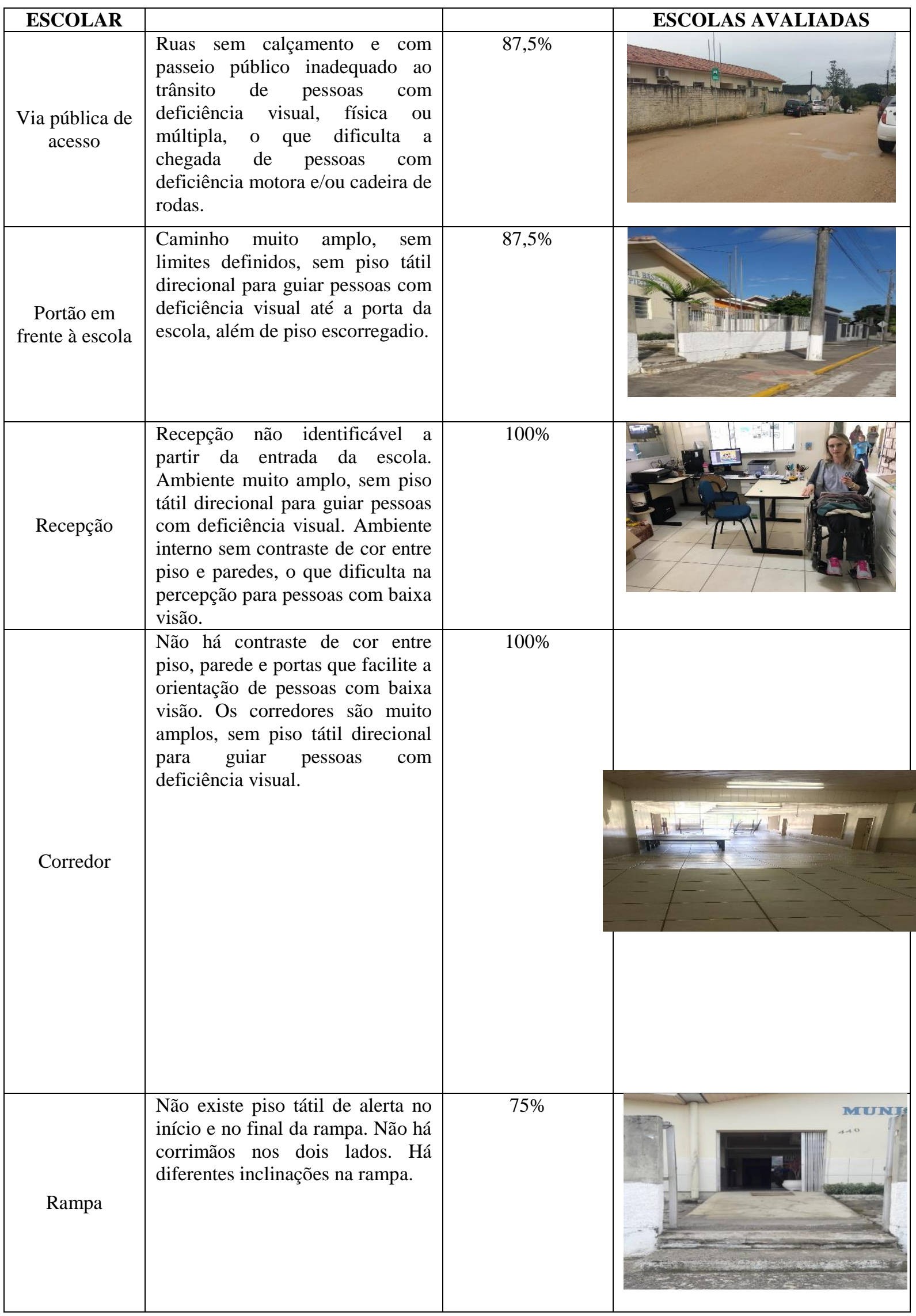




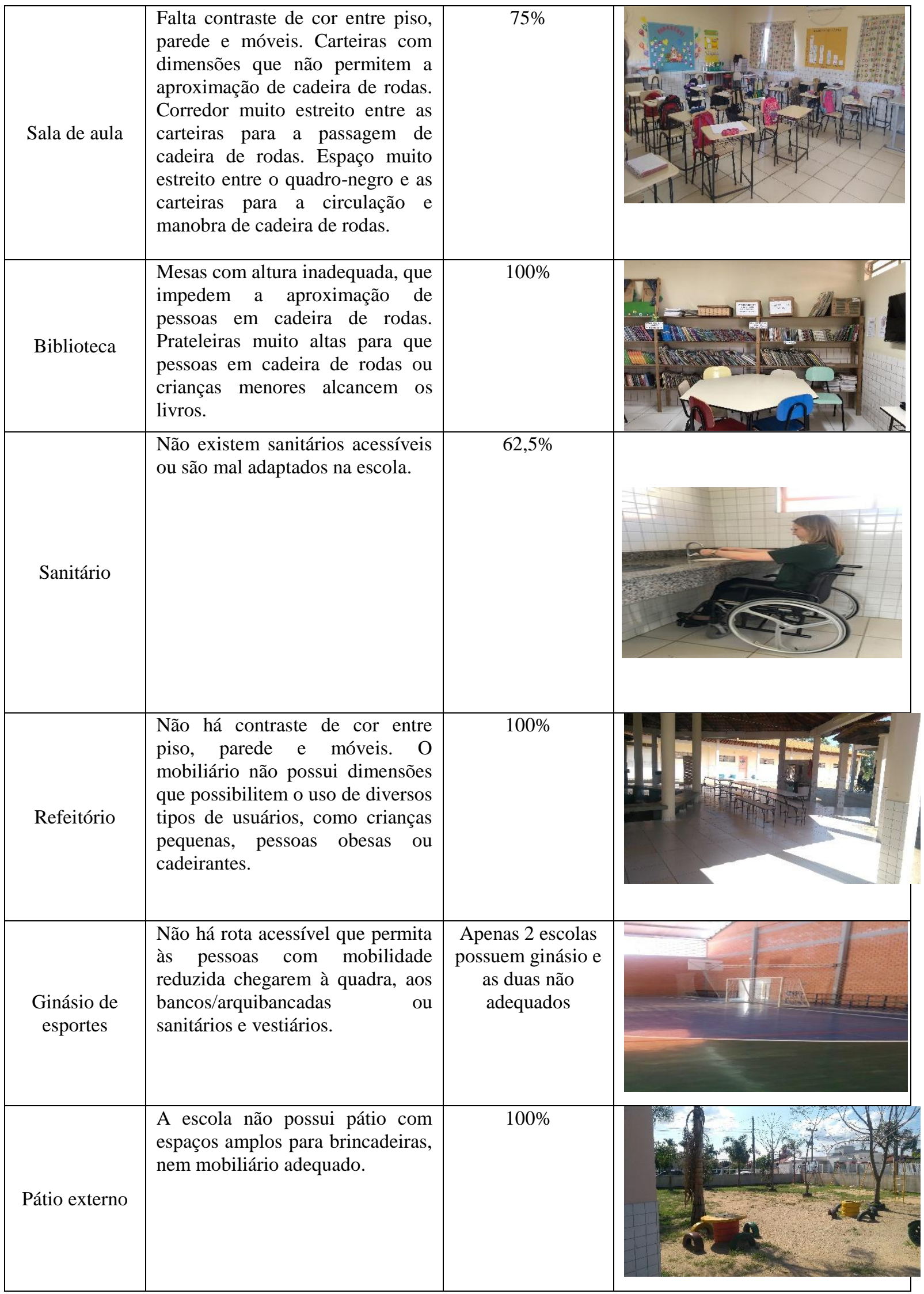

Fonte: Autores, 2020.

Registra-se que nas escolas contempladas com verbas do Programa Dinheiro Direto 
na Escola (PDDE)para a "Escola Acessível” ou outros recursos, haviam algumas adaptações como rampas de acesso na entrada da escola. A maioria dessas escolas informaram que as adaptações referente à inclusão ocorriam, com maior frequência, na aquisição de materiais e equipamentos para uso nas salas de aula, como auxílio aos alunos com dificuldade de aprendizagem; e que as verbas recebidas geralmente, não eram suficientes para as adaptações físicas necessárias.

A avaliação realizada deixou evidente a falta de coerência entre as normativas (especialmente a NBR 9050) e o que realmente acontece na prática. O espaço físico não está adequado para receber alunos com diferentes deficiências. $\mathrm{O}$ que continuamente fora relatado como um problema a ser resolvido assim que houvesse uma matrícula. A falta de acessibilidade dos espaços e o modo como estes estão organizados fazem com que os alunos com deficiências se tornem dependentes da ajuda alheia, apesar de possuírem legalmente o direito à autonomia, conforto e segurança.

O desafio da acessibilidade está colocado para a educação desse município (bem como de muitos outros no Brasil) e o que se percebeu, é que seus pressupostos não estão restritos ao trabalho de determinados profissionais, mas direcionados para toda a sociedade. Nesse sentido, acredita-se que a parceria junto ao Observatório Social implicou no despertar do assunto pela entidade, que em sua essência representa a sociedade civil. Viabilizar acesso igualitário, é permitir então, que a sociedade aprenda e conviva com a inclusão em suas diferentes esferas, ocorrendo assim, a concretização de projetos escolares inclusivos.

Registra-se que os relatórios entregues pelo projeto de extensão "Observatório Acessível" constituem-se importante ferramenta para que os gestores escolares tomem decisões mais assertivas e com embasamento técnico no que se refere a acessibilidade espacial, porque foram apresentadas soluções para os problemas encontrados (Figura 4). Pois o que se percebeu nas visitas foi a sensibilização da comunidade escolar para o tema, mas a dificuldade financeira e de recursos humanos, além da grande parte das edificações serem antigas e mal estruturadas, o que faz com que sejam pontuais as ações para acessibilidade espacial. 
Figura 4: Exemplo de parte do relatório entregue às escolas.

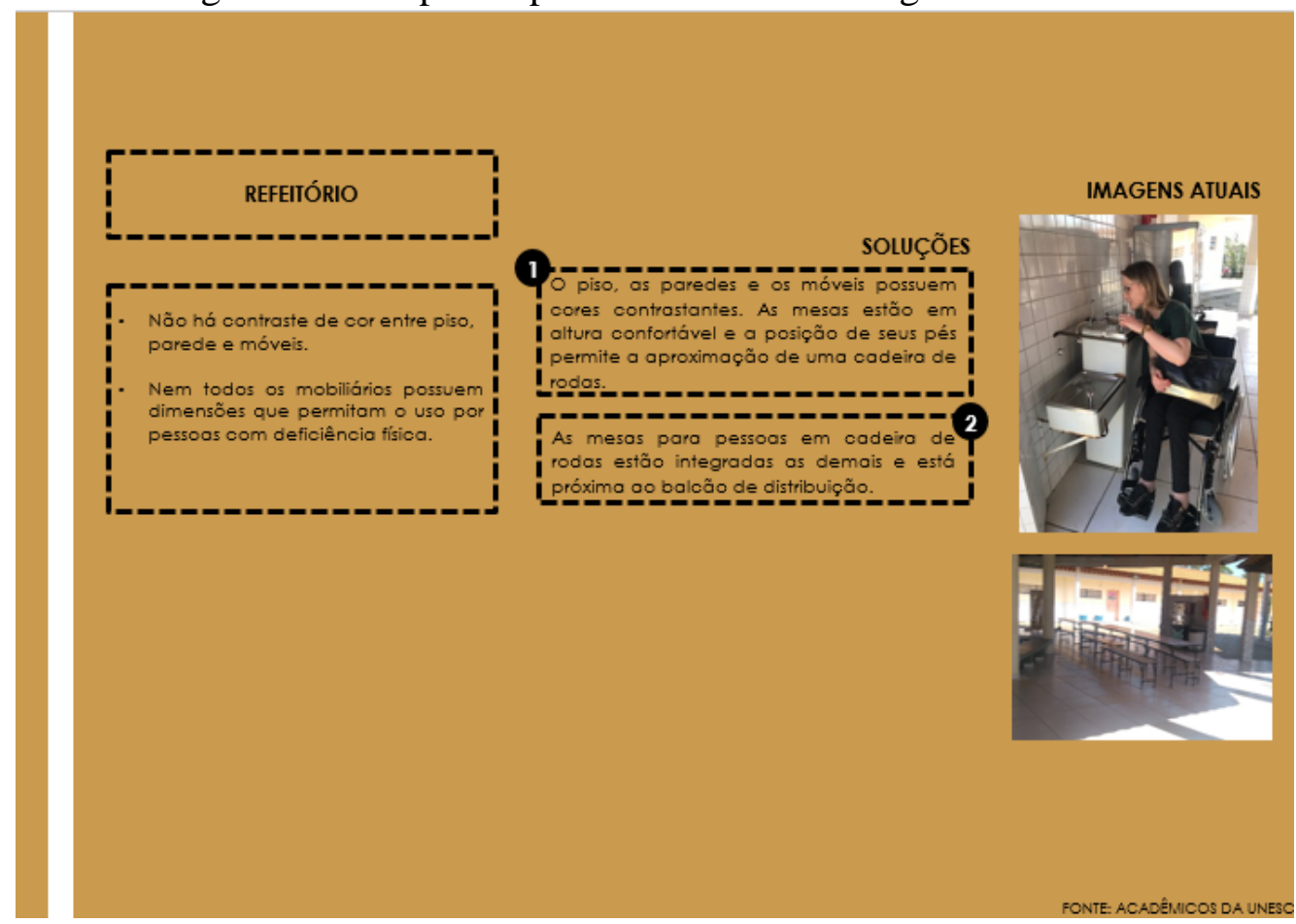

Fonte: Autores, 2019.

De modo geral, a inserção dos três cursos - Arquitetura e Urbanismo, Design de Produtos e Engenharia Civil - promoveu a troca de informações técnicas, adquiridas pelos extensionistas nos respectivos cursos, e as oriundas da comunidade escolar, conhecedora de sua realidade, provocando assim, a reflexão sobre os problemas sociais existentes. Além disso, a interdisciplinaridade promovida pela participação de diversos profissionais,principalmente da área técnica, trouxe a percepção da dinâmica ecológica ao planejamentodo espaço.

\section{CONSIDERAÇÕES FINAIS}

O tema da acessibilidade em espaços públicos é de extrema importância e urgência nas cidades brasileiras, e consequentemente o uso de tecnologias assistivas para minimizar a notória exclusão das pessoas com deficiência do convívio comunitário. No Brasil,segundo a Pesquisa Nacional de Saúde de 2013 (última estimativa realizada) há 200,6 milhões de pessoas residentes em domicílios particulares permanentes. Do total, 6,2\% possuem pelo menos uma das quatro deficiências (visual, auditiva, física ou intelectual).Desse universo, grande parte não tem acesso e efetiva participação nas atividades sociais, mesmocom a série de leis e normativas que garantem a universalidade de direitos. Dentre os motivos para isso, está a falta de acessibilidade espacial nas edificações de uso público. 
Nesse sentido, acredita-se que a parceria junto ao Observatório Social implicou no despertar do assunto pela entidade. Os trabalhos junto à comunidade escolarpromoveram inovações "incrementais", ao colaborar para o processo de mudança da escola frente a realidade da pessoa com deficiência. Por se tratar de um projeto com metodologia participativa ("pesquisa-ação"), houve continuamente o envolvimento com reflexão acerca do tema (acessibilidade espacial) e consequente, mudanças em esfera local (nas escolas visitadas) e maiores, no cotidiano social.

A própria metodologia - "Manual de AcessibilidadeEspacial para Escolas: o direito à escolaacessível" - é de acesso público, mas pouco ou nada utilizada e compreendida. Assim, a medida que a comunidade se apropriou desse conhecimento, o mesmo pode ser implantado inclusive a outras edificações do município, como constatou-se nas iniciativas (a parte) realizadas pelo Observatório Social.

O contato com as condições de acessibilidade espacial nas escolas de Morro da Fumaça permitiu compreender que as mesmas refletem um cenário nacional; e mesmo aquelas que passaram por adequações de espaços, ainda não foram satisfatórias na integralidade das ações de inclusão. As imagens apresentadas atestaram isso.

O conceito de inclusão, perpassa a acessibilidade espacial, mas está diretamente relacionado ao cotidiano dos alunos e sem esse requisito, muitos não têm as mesmas oportunidades constitucionalmente definidas. Dessa forma, é possível compreender que a adaptação do ambiente escolar envolve um processo sistêmico que inclui diversos setores interligados ao desenvolvimento da política de educação sob a perspectiva da inclusão.

Encerra-se afirmando que a Universidade, através da extensão, influencia e também é influenciada pela comunidade, ao permitir a troca de valores. A extensão universitária permite que conhecimentos técnicos sejam confrontados com cenários reais. A visão interdisciplinar Arquitetura e Urbanismo, Design de Produtos e Engenharia Civil - possibilitou a troca de conhecimentos e reformulação de conceitos antes só vistos na literatura técnica e de maneira isolada. Percebem-se repercussões nos extensionistas e na comunidade externa, entendendose como positivos os resultados alcançados não somente no âmbito da aprendizagem, mas na possibilidade de contribuir com o processo de tomada de consciência do real para que a promoção de mudanças efetivamente aconteça.

\section{Agradecimentos}


Agradecimentos especiais à Universidade do Extremo Sul Catarinense (UNESC), Pró-Reitoria Acadêmica (PROACAD) e Diretoria de Extensão, Cultura e Ações Comunitárias. Ao Observatório Social de Morro da Fumaça, a Secretaria de Educação do município e a comunidade escolar, especialmente representada pelas direções e coordenações pedagógicas. Bem como às professoras Glaucia Regina Marchesan e Rúbia Carminatti Peterson; aos acadêmicos: Amanda Matos, Ana Maria Ghellere, Ana Luiza Colonetti, Douglas S. Santos, Felype Moretti, Giovana Scheffer Maggi, Leticia Alberton Baggio, Richard Cunha Cardoso,Tainá Francisco PirolaeWelinton Borges Matias; e às arquitetas e urbanistas Jéssica H. Eyng eLays Juliani Hespanholcujas contribuições enriqueceram o projeto no decorrer de sua vigência.

\section{Fontes de financiamento}

Fonte de financiamento do Edital $n^{\circ} 101 / 2018$, da Universidade do Extremo Sul Catarinense.

\section{REFERÊNCIAS}

ABATE, Tânia P.; KOWALTOWSKI, Dóris C. C. K.; BERNARDI, Núbia. Questões Éticas na Pesquisa em Avaliação Pós-Ocupação (APO). In: ENCONTRO NACIONAL DE TECNOLOGIA DO AMBIENTE CONSTRUÍDO, Maceió, 2014.

ARAN, Artur P. Introdução. In: ALCUDIA, Rosa. Atenção à diversidade. Porto Alegre: Artmed, 2002. p. 11-12.

ASSOCIAÇÃO BRASILEIRA DE NORMAS TÉCNICAS. NBR 9050: Acessibilidade de pessoas portadoras de deficiência a edificações, espaço, mobiliário e equipamentos urbanos. Rio de Janeiro: ABNT, 2015.

BRASIL. Censo Escolar Da Educação Básica 2019. Brasília, DF. Disponível em: http://portal.inep.gov.br/web/guest/resultados-e-resumos. Acesso em 12 maio 2020.

Censo Escolar/INEP 2018. Brasília, DF. Disponível em: https://www.qedu.org.br/cidade/2147-morro-da-fumaca/censo-escolar. Acesso em 13 maio 2020.

Secretaria de Educação Especial. Política Nacional de Educação Especial na Perspectiva da Educação Inclusiva. Brasília, DF, jan. 2008.

Constituição da República Federativa do Brasil: Texto Constitucional promulgado em 5 de outubro de 1988. 35. ed. Brasília: Câmara dos Deputados / Edições Câmara, 2012. 
BINS-ELY, Vera H. M.; BRANDAO, Milena M.; BERTOLETTI, Roberta. Acessibilidade Espacial no Centro Tecnológico da UFSC: avaliação e proposição de soluções projetuais. Florianópolis, 2010.

CARVALHO, Telma Cristina Pichioli de. Arquitetura escolar inclusiva: construindo espaços para educação infantil. Tese (Doutorado). Universidade de São Paulo, São Carlos, 2008.

COMITÊ DE AJUdAS TÉCNICAS. Tecnologia Assistiva. Brasília: CORDE, 2009. 138 p.

DISCHINGER, Marta; BINS ELY, Vera; PIARDI, Sonia. Promovendo acessibilidade espacial nos edifícios públicos. Florianópolis, SC: MPSC, 2012.

Marta; et al. Manual de AcessibilidadeEspacial para Escolas: o direito à escolaacessível. Brasília: Ministério da Educação, Secretaria de Educação Especial, 2009.

FREIRE, Paulo. Pedagogia da esperança - um reencontro com a Pedagogia do oprimido. Rio de Janeiro: Ed. Paz e Terra, 1992.

KOWALTOWSKI, Doris C. C. K. Arquitetura escolar: o projeto do ambiente de ensino. São Paulo: Oficina de Textos, 2011. 272 p.

MICHELS, M. H. O que há de novo na formação de professores para a Educação Especial?In: Revista Educação Especial, Santa Maria, RS, v. 24, n. 40, p. 219-232, 2011.

PADILHA, Caio Augusto Toledo. Educação e inclusão no Brasil (1985-2010). 2014. 391 f. Dissertação (Mestrado). Faculdade de Educação da Universidade Estadual de Campinas, Campinas, 2014.

OBSERVATÓRIO SOCIAL. Regulamento do Observatório Social. 2018.

ORGANIZAÇÃO DAS NAÇÕES UNIDAS. Convenção sobre os Direitos das Pessoas com Deficiência, aprovada pela Assembleia Geral da ONU em dezembro de 2006.

THIOLlENT, Michel. Metodologia da Pesquisa-Ação. São Paulo: Cortez, 2005. 